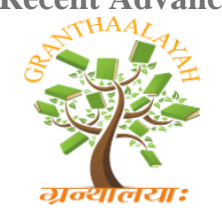

$$
\begin{gathered}
\text { INTERNATIONAL JOURNAL OF RESEARCH - } \\
\text { GRANTHAALAYAH } \\
\text { A knowledge Repository }
\end{gathered}
$$

RACEEE - 17

\title{
SMART STORAGE WITH WEB SERVER INTERFACED
}

\author{
Deepu Dharshan $S^{* 1}$, Supritha $S^{2}$, Suma D $S^{3}$, Vinay Kumar $S B^{4}$ \\ ${ }^{* 1,2,3} 6^{\text {th }}$ Semester B.Tech., Department of Electronics and Communication Engineering, School \\ of Engineering and Technology, Jain University, Bangalore-562112, India \\ ${ }^{4}$ Assistant Professor, Department of Electronics and Communication Engineering, School of \\ Engineering and Technology, Jain University, Bangalore-562112, India
}

DOI: https://doi.org/10.29121/granthaalayah.v5.i4RACEEE.2017.3318

\begin{abstract}
Smart storage with web server interfaced is the new trend which takes leap and puts effort in saving lives. It works by connecting all devices together to give the required stock update. This can be used in many places where stock can't be updated manually and given to the customers. Our product will make this happen which maintains a healthy relationship between customers, retailers and the production house. It is designed to overcome the present method which we consider to be traditional. Traditional method is the manual updating of stocks which isn't retailer or consumer friendly. Our product is designed in such a way that the stocks are auto updated with least human interaction.
\end{abstract}

Keywords: Object Detecting Sensors; Blood Banks; Database; Stock Update; Server; Ph Sensors; IOT Module; GSM Module.

Cite This Article: Deepu Dharshan S, Supritha S, Suma D S, and Vinay Kumar S B. (2017). "SMART STORAGE WITH WEB SERVER INTERFACED." International Journal of Research - Granthaalayah, 5(4) RACEEE, 23-28.

\section{Introduction}

The main aim of the project is to innovate something new for a good cause [4]. The repeated day to day problems faced by the society led to the invention of this project. Taking into consideration of what's happening in this society, many people die without getting their rare unfortunate blood group. The main mission of the project is to keep the track of blood bottles in blood banks and give an update of the databases on the website by means of graph. In case the required blood bottle is not there then the system sends them an SMS of the list of numbers of people who are ready to donate. Talking about the present scenario, if a person is met with an accident, and requires a rare blood group say $\mathrm{AB}$ - or o-, the concerned person has to roam around for blood banks to find the required blood or post it on social media requesting for donors. Let me just forget about what is happening in others life, recently I received messages 
Recent Advances in Communication, Electronics \& Electrical Engineering

twice on social media requesting for $\mathrm{AB}$-ve donors and to be frank this isn't the first time something like this has happened. As no action is taken over this issue it happens almost every day.

The innovation in this idea requires less human interference and is totally automated. It requires less human interference and is totally automated. And it is used in places where commodities are kept in large quantities. The components are linked together and fed into a server which can be accessed through a website.

\section{Method's Adopted So Far}

The present method adopted is updating the database manually. This method requires a lot of human interference and kills too much of the precious time. This method isn't user or retailer friendly [3]. People used to wander around and roam in search of the required rare blood group and in case they don't find it? They will have no choice but to buy it for higher price from red market or just forget the thought of getting their loved ones back. This method is much tedious and complex [1].

\section{Case Studies}

Case study 1: Recently while doing the project, we came across posts posted on the social media for example whatsapp. The figure below shows the message posted on a group requesting for blood donors. Unfortunately that blood group was the rarest blood group. We did forward the message, but we weren't aware of what happened to the victim.

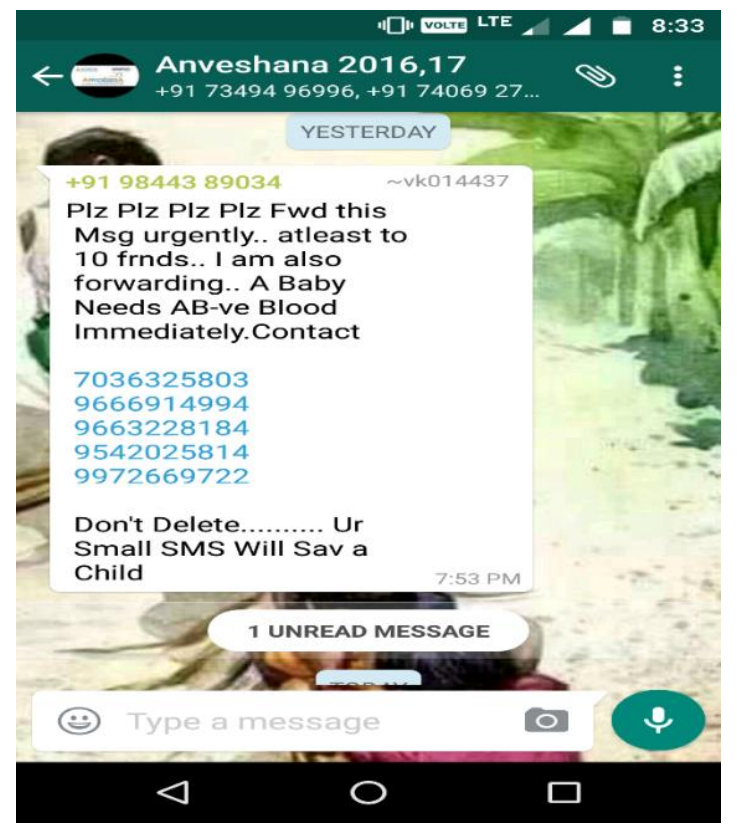

Figure 1: A Post Received On Whatsapp Group Requesting For AB-Ve Blood Donors. 
Recent Advances in Communication, Electronics \& Electrical Engineering

Case study 2: Just few days later there was another post, moreover a message on another group requesting for blood donors. This time also it was about the rarest blood. O-ve is also another rarest blood group.

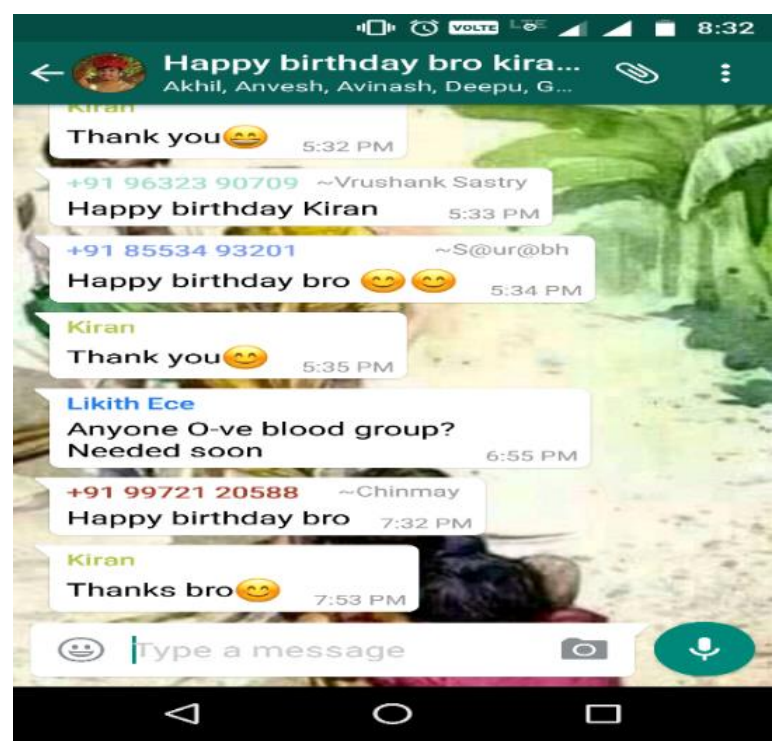

Figure 2: Post Received On Whatsapp Group Requesting For O-Ve Blood Donors.

\section{Methodology}

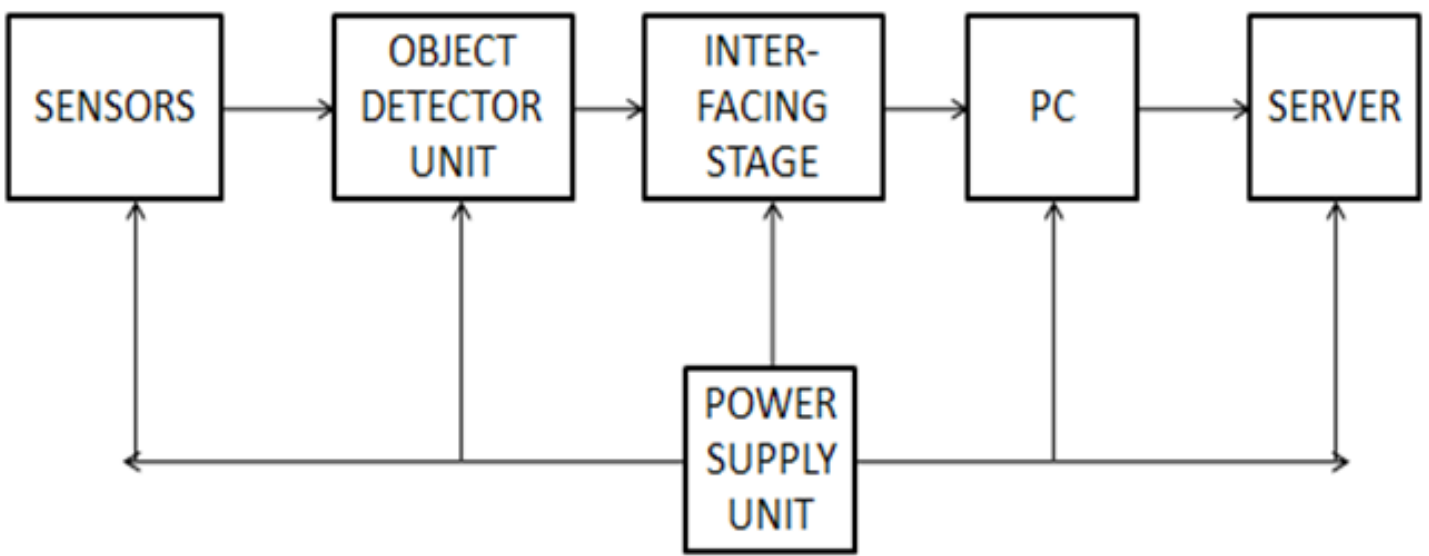

Figure 3: Block Diagram Representation of the Proposed Project

\subsection{Sensors}

Sensor is a device which responds to the input fed from the environment. There are so many sensors such as touch sensors, temperature sensors, IR sensors, proximity sensors, pressure sensors, level sensors, smoke and gas sensors, Ultrasonic sensors. The project uses object detecting sensors or IR sensors. The object detecting sensors are fitted in the place where blood bottles are preserved, one sensor for one bottle for more precision. These sensors transmit infrared rays for detecting the object and if no object is found, then it produces an NO Object signal and this is fed to Object Detector Unit for further processing. 


\subsection{Object Detector Unit}

The main unit that is required to generate an NO Object alert signal corresponding to the signal produced by object sensors, which is in server's TTL format. This produces the TTL signal for server, which is understood to be an alert signal and this is fed to input of server by using a suitable Interfacing stage.

\subsection{Interfacing Stage}

Interfacing circuits are the main component which acts like a translator and converts the human understandable input or the physical inputs into server understandable language. The server needs TTL (transistor to transistor logic) compatible level signal at its input port, so this stage produces the TTL level signal and sends it to the server for updating the databases on to the website or the app.

\subsection{Personal Computer (PC)}

This is the Monitoring unit of our system which has software embedded into its memory, this scans its input port for any alert signal update. In case any such signal is found, it will automatically deduct the blood bottle database for one less count. So after each pre-determined time interval the updated data base is then sent to the Server, which is accessed by user/owner for the database.

\subsection{Server}

The database received by the field sensors and it is updated to the web, where the retailer and the customer can access it from any place across the globe.

\subsection{Power Supply}

It is designed to supply regulated power. Which gives the required voltage for its working.

\section{Result and Discussion}

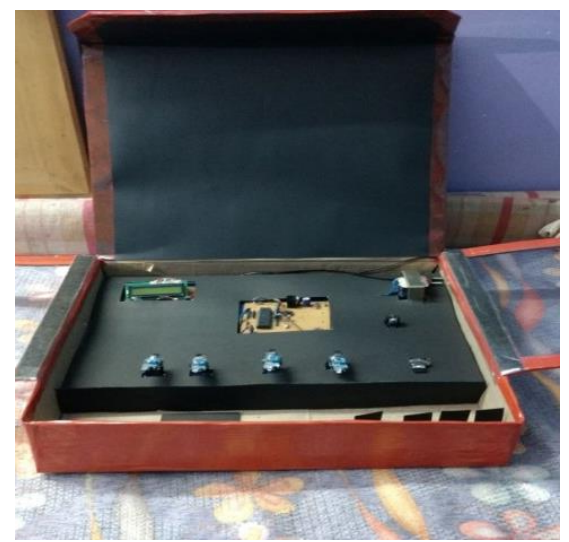

Figure 4: Working Hardware Model 
Recent Advances in Communication, Electronics \& Electrical Engineering

\section{$\square$ ThingSpeak $^{\text {Tu }}$}
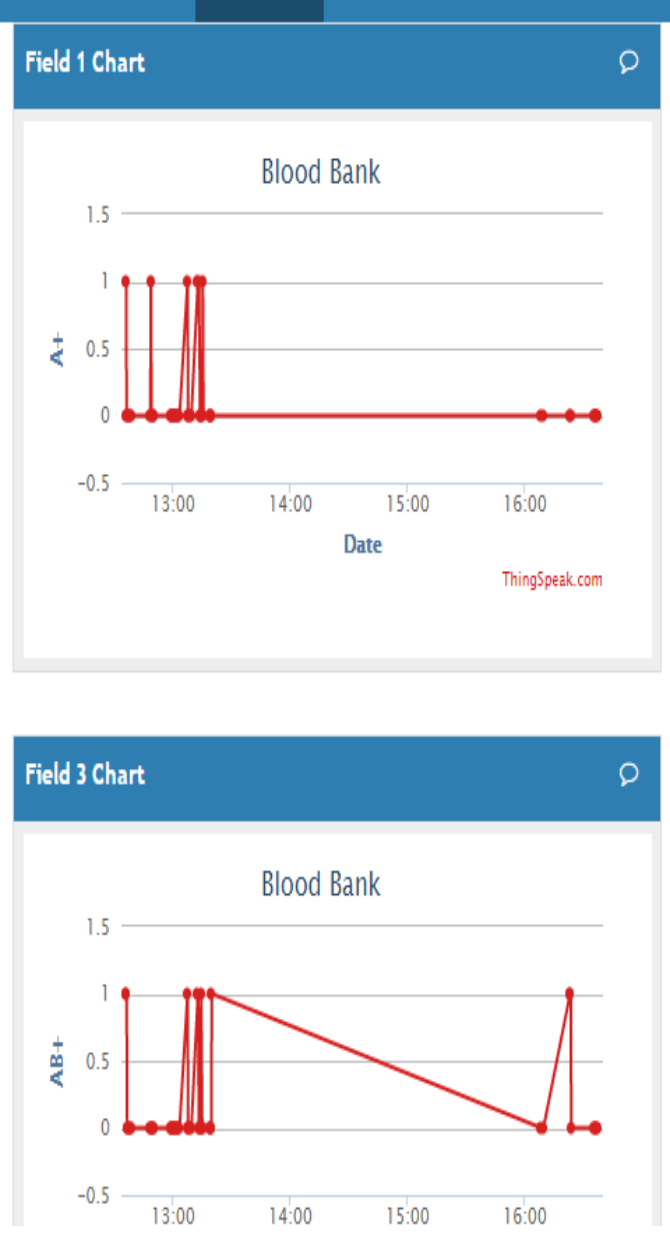

Figure 5: The Database Available On the Website

This is an overlook of the working model of the project, as seen in figure 4, the sensors used is to detect whether there's a presence of an object or not. As the data gets recorded by the circuit it will get updated to the website. The website view of the project result is as shown in figure 5, this is data recorded by the sensors. It shows us the high-low graph. High stands for a presence of the blood bottle and low stands for the absence of it. This website can be viewed from across the globe, where the customer and the retailer can access it.

As it's known that during emergency situations of the rarest blood group it is very much difficult to find donors, so what the person does is he posts it on social media asking for donors or he will go to blood bank, but what happens if the rare blood bottle isn't present or the donor isn't there? So instead of doing all this and wasting time he can directly visit the website and access it and go get the bottle as soon as possible to save the victim [1] And if the bottle isn't available, then it sends an SMS to the person giving them the contacts of people who are ready to donate. 
Recent Advances in Communication, Electronics \& Electrical Engineering

Project contributes in stopping smuggling of these bottles because if one bottle is removed then it will be updated, so the owner will have real-time update and he can stop it from getting stolen. If it's not stolen or smuggled it won't enter the red market and be sold for the illegal and unacceptable price.

\section{Conclusion}

The project is very much user friendly and it will help in saving life as it can be accessed any time and it is totally automated and requires less human interference[2]. The model is cost effective and compact in size. It is also a matter of safety because the manager or the owner can keep a track of their commodities. By increasing the number and quality of sensors it can be used in many other places such as railway stations, warehouse. It can also be used in antitheft system and this helps us in eliminating cabling. Material needed by people are displayed on screen making it user friendly, hence pseudo marketing and artificial scarcity is reduced. Here the common man can access and view in any corner of the globe. IOT module can be interfaced along with GSM module by enabling it to work even without internet. $\mathrm{pH}$ sensors and high precision sensors can be interfaced for accurate values of stock. This paper highlights on betterment of human life saving methods with less human interference.

\section{References}

[1] Putta Sindhuja, M. S. Balamurugan "Smart Power Monitoring and Control System through Internet of things using Cloud Data Storage," Indian Journal of Science and Technology, Vol 8(19), August 2015.

[2] Zhang Fan and Luo Xing-guo, "Design and Verification of Reconfigurable WEB Cloud Access Device based on Smart Hybrid Storage" 2013 International Conference on Computational and Information Sciences.

[3] R.J.W. de Groot, "Smart Storage: Embedding Local Storage in the Distribution Grid."

[4] Ruchika Lahare, Gayatri Shinde, Bhakti Sontakke, Sayali Tambe "Smart Storage for Home Application," International Research Journal of Engineering and Technology (IRJET), Volume: 04 Issue: 01 | Jan -2017. 